\title{
The ageing population in healthcare: a challenge to, and in, the workforce
}

Welcome to the August edition of Clinical Medicine. I think it would be fair to say that since I wrote my last editorial much has changed in the healthcare landscape and, despite many people's misgivings about the recent general election, the outlook for patients and staff in the NHS may have unexpectedly been improved, with a government that is now mandated to listen, if it wishes to stay in power. We, the NHS, need them to listen, and more importantly to start responding, to our concerns.

In addition to the changed political landscape, the combined tragedies of the Manchester, Westminster and London Bridge terror incidents and the subsequent Grenfell Tower disaster have required all emergency services, including medical staff, to respond in terrible and tragic circumstances. This response is rightly described as heroic in the lay press, but, as we must continue to point out to ministers and those who control our purse strings, this is how we aim to respond to all our patients, providing life-saving and supportive care every minute of every day, not just in the nation's darkest hours. Of course, we do this in the UK, for our own population, but as outlined in this journal, we also do so during international crises, such as the recent Ebola epidemic. ${ }^{1}$

We all know that the NHS is under enormous strain, and will continue to be so for many years to come. A publicly funded NHS model will remain under critical pressure with a government committed to austerity, but at least extra taxation to underpin its future was committed to by both opposition parties and is now forming part of the national debate. What is missing, however, is discussion on the additive effect of the ageing population, not just of the patients, but also the workforce.

In this issue, the excellent CME section focuses on the care of the older patient, highlighting the need to manage the complexity of this growing population with pragmatism, respect and dignity, focusing on frailty as the primary driver, rather than chronological age. Whether in the acute admission ${ }^{2}$ or perioperative setting, ${ }^{3}$ or on the ward, we must ensure the environment we provide this cohort is safe, both physically and emotionally. As is highlighted, our decision making must be underpinned by the mantra 'no decision about me, without me', which is of utmost importance in this vulnerable population. The article by Khizar and Harwood ${ }^{4}$ provides a useful handrail in this difficult area. Reducing falls ${ }^{5}$ and being aware of the physiology of ageing ${ }^{6}$ all support optimal care of the aged and frail patient on our medical wards.

As I have highlighted in previous editorials, retaining generalist expertise in the era of sub-specialisation is a real challenge and I suspect for many of us that this applies particularly in the areas of acute neurology, cardiology and oncology. Access to neurology expertise is essential to provide optimal care in the acute setting; however, in many hospitals colleagues working in acute medicine do not have rapid access to specialist neurology advice, and this impacts adversely on both acute care and the discharge of less clinical serious cases. The multidisciplinary example articulated by Nitkunan $e t a l^{7}$ provides a potential model that could help upskill the entire acute medical workforce on the AAU, as well as providing immediate specialist reassurance to support early discharge, and filtered, but rapid, access to consultant level expertise when required.

With survival rates for cancer ever improving, the management of comorbid conditions takes on a greater importance; at the same time, maintaining knowledge of common cardiovascular conditions (such as heart failure and hypertension) is essential for all general physicians. These important areas are covered in detail within this edition in high quality and readable articles. ${ }^{8-10}$ Maintaining our clinical knowledge and how we would like to receive CPD to support our practice is highlighted in a fascinating article from Ireland, ${ }^{11}$ while the way we feed back to our trainees, via their online portfolios, could certainly be improved, especially in acute medical specialties, based on the evidence presented by Tham et al. ${ }^{12}$ The pressure of time and the multiple demands placed on a stretched workforce certainly play into this, but we owe it to both our trainees and our patients to ensure we take

$\begin{array}{ll}\text { Members of the editorial board } & \\ \text { Wing Commander Edward Nicol } & \text { Dr Michael Almond } \\ \text { Editor-in-chief } & \text { Mr Paul Belcher } \\ & \text { Dr Rodger Charlton } \\ \text { Cono Ariti } & \text { Dr Tim Chevassut } \\ \text { Statistical editor } & \text { Prof Tahseen Chowdhury } \\ & \text { Dr Albert Edwards } \\ \text { Nick Cork } & \text { Dr Kate Evans } \\ \text { Medical student representative } & \text { Dr Johanna Feary } \\ & \text { Dr Maggie Hammersley } \\ & \text { Dr Dylan Harris } \\ & \text { Prof Brian Hurwitz }\end{array}$

Members of the editorial board

Wing Commander Edward Nicol

Cono Ariti

Nick Cork

Medical student representative
Dr Nicola Jones

Dr Vikas Kapil

Dr Alexandra Lake

Dr Tom Levett

Dr Nicola Lomax

Prof Philip MacCarthy

Prof Yash Mahida

Dr Chris Marguerie

Dr Ravik Mascarenhas

Prof Martin McKee

Dr Andrew Medford
Dr Rahul Mukherjee

Dr Mehool Patel

Dr Gerrard Phillips

Dr Roby Rakhit

Dr Jo Rimmer

Prof Phil Smith

Dr Angela Star

Prof Cameron Swift

Dr Rhys Thomas

Dr Duncan Wilson

Dr Juliet Wright 
the time to give meaningful, honest and actionable feedback to the next generation of physicians.

In addition to the ageing and increasingly complex patient population described above, and the relentless pressure on the medical workforce, other government-driven agendas are also squeezing our senior and overseas colleagues. The cap on lifetime taxable allowance for pensions is, against a challenging work environment, pushing some our most experienced and qualified colleagues to seek earlier retirement or return to work in a less than full-time capacity. In addition, both the Brexit negotiations and the government's inflexible immigration and visa policies mean that the ability of the NHS to recruit and retain staff at this critical time (to fill an ever-increasing number of consultant and training post vacancies) is challenging, with rota gaps increasingly prevalent. This is not just true in hospital medicine but also in primary care, where the NHS has relied, to a large degree, on a workforce who came to the UK at a time when we were more welcoming to those from overseas.

So, the ageing population is not an issue confined to those we care for, but also applies to those who care. This is a looming crisis and one the RCP is working hard to address both with employers and at government level. Dealing with the issue of ageing is essential for us and our patients if the NHS model is to prevail in the 21 st century.

\section{References}

1 Reece S, Brown C, Dunning J et al. The UK's multidisciplinary response to an Ebola epidemic. Clin Med 2017;17:332-7.
2 Conroy S, Parker S. Acute geriatrics at the front door. Clin Med 2017;17:350-3.

3 Gordon AL, Evans BJ, Dhesi J. The physician's role in perioperative management of older patients undergoing surgery. Clin Med 2017;17:357-9.

4 Khizar B, Harwood RH. Making difficult decisions with older patients on medical wards. Clin Med 2017;17:353-6.

5 Morris R, O'Riordan S. Prevention of falls in hospital. Clin Med 2017;17:360-2.

6 Offord NJ, Witham MD. The emergence of sarcopenia as an important entity in older people. Clin Med 2017;17:363-66.

7 Nitkunan A, MacDonald BK, Boodhoo A et al. A hyperacute neurology team - transforming emergency neurological care. Clin Med 2017;17:298-302.

8 Kapoor A, Prakash V, Sekhar M et al. Monitoring risk factors of cardiovascular disease in cancer survivors. Clin Med 2017;17:293-7.

9 McCallum L. Hypertension - state of the art 2017. Clin Med 2017;17:338-40.

10 Callan PD, Clark AL. Heart failure - what's new and what's changed? Clin Med 2017;17:341-6.

11 Maher B, Faruqui A, Horgan M et al. Continuing professional development and Irish hospital doctors: a survey of current use and future needs. Clin Med 2017;17:307-15.

12 Tham TCK, Burr B, Boohan M. Evaluation of feedback given to trainees in medical specialties. Clin Med 2017;17:303-6.

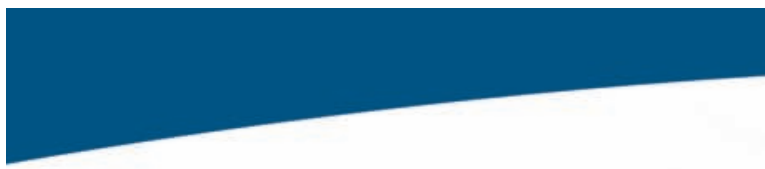

Wing Commander Ed Nicol Editor-in-chief

\section{Join the discussion online}

in 6 You $f$

www.linkedin.com/company/royal-college-of-physicians www.twitter.com/Clin_Med www.youtube.com/rcponline www.facebook.com/royalcollegeofphysicians

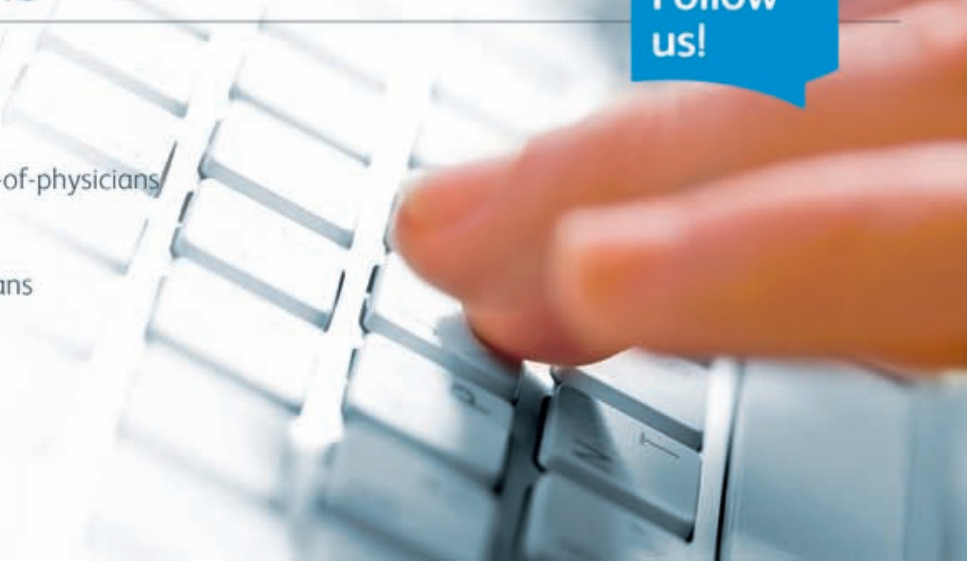

